\title{
CARBENdAZIM e O MEIO AMBIENTE: DEGRADAÇÃO E TOXIDEZ
}

CLÁUDIAF. B. COUTINHO*

ANDRESSA GALLI*

LUIZ H. MAZO**

SERGIOA. S. MACHADO**

\begin{abstract}
Este artigo apresenta breve revisão de literatura sobre o fungicida carbendazim, muito utilizado em culturas de frutas e vegetais no Brasil. Foram abordados, principalmente, a degradação (abiótica e biótica) e os efeitos tóxicos que o fungicida carbendazim promove aos animais e aos seres humanos. Devido ao uso intenso de carbendazim, esse fungicida tornou-se poluente muito persistente no solo e na água. Os estudos de degradação são importantes para 0 isolamento e caracterização de microrganismos capazes de degradar o fungicida, e também para o desenvolvimento de processos abióticos (fotodegradação) a serem utilizados no tratamento de água e solo poluídos.
\end{abstract}

PALAVRAS-CHAVE: DEGRADAÇÃO; FUNGICIDA - TOXIDEZ; CARBENDAZIM.

* Doutorandas em Química Analítica, Universidade de São Paulo, Instituto de Química de São Carlos, SP (e-mail: claudiabreda@iqsc.usp.br; andressa@iqsc.usp.br).

** Pesquisadores, Universidade de São Paulo, Instituto de Química de São Carlos, SP (e-mail: Ihmazo @iqsc.usp.br; sasmach@iqsc.usp.br). 


\section{INTRODUÇÃO}

A introdução dos fungicidas sistêmicos do grupo dos benzimidazóis, na década de 60 , tornouse um marco na história do desenvolvimento dos fungicidas. Os benzimidazóis são utilizados no tratamento de sementes e de solos e em aplicações foliares (SILVA et al., 1999; PICINNI, 1994). Dentre os fungicidas desse grupo, os mais utilizados são: benomil, tiofanato-metílico e carbendazim (MAZELLIER, LEROY e LEGUBE, 2002). No Brasil, os benzimidazóis são aplicados em culturas de algodão (sementes), citros (folhas), feijão (sementes e folhas), soja (sementes e folhas), trigo (folhas) e numa grande variedade de frutas e vegetais. Os limites máximos de resíduos (LMR) e intervalos de segurança desses fungicidas em alimentos são estabelecidos pela Agência Nacional de Vigilância Sanitária (ANVISA, 2006).

O fungicida benomil é rapidamente convertido à carbendazim no meio ambiente, com tempo de meia-vida de 2 e 19 horas em água e solo, respectivamente (SANDAHL, MATHIASSON e JONSSON, 2000; SINGH e CHIBA, 1993; SANCHEZ-RASERO, ROMERO e DIOS, 1991). A Figura 1 apresenta a fórmula estrutural dos fungicidas benomil, carbendazim e tiofanato-metílico.

\section{FIGURA 1 - FÓRMULA ESTRUTURAL DOS FUNGICIDAS BENOMIL, CARBENDAZIM E TIOFANATO-METÍLICO}
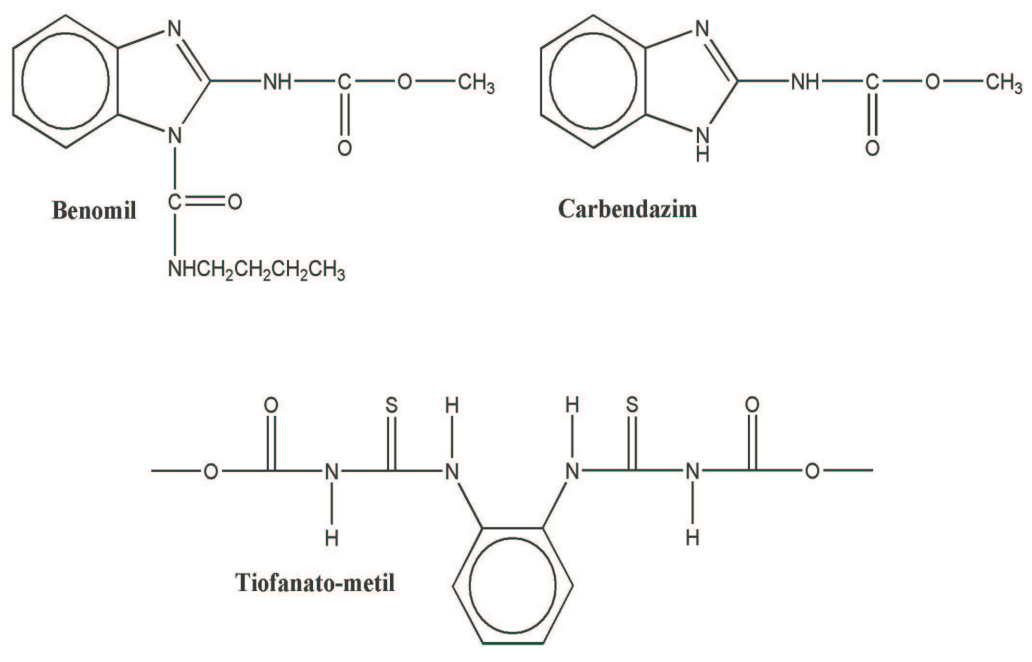

Carbendazim constitui o ingrediente ativo mais utilizado do grupo dos fungicidas benzimidazóis (BOUDINA et al., 2003) contra grande variedade de doenças, como as causadas pelos fungos Ascomicetos spp., Basidiomicetos e Deuteromicetos spp. em culturas de frutas e vegetais (HUTSON e JEWESS, 1999).

Os benzimidazóis atuam nos fungos pela inibição de proteínas específicas, chamadas de $\alpha$ e $\beta$ tubulinas (DAVIDSE, 1988), que mediante polimerização constituem os microtúbulos (LEROUX, 2003). Quando essas proteínas entram em contato com tais fungicidas a formação dos microtúbulos é inibida. Como resultado as células não se dividem e passam a ser multinucleadas, levando o fungo à morte (BASF, 2006). A Figura 2 apresenta o esquema do mecanismo de ação do carbendazim.

Devido ao uso intenso, o carbendazim tornou-se poluente muito persistente tanto no solo quanto na água (FERNANDEZ et al., 2001). Esta revisão examinou as propriedades físico-químicas, a degradação abiótica e biótica e os efeitos tóxicos que o fungicida carbendazim promove aos animais e aos seres humanos. 


\section{FIGURA 2 - ESQUEMA DO MECANISMO DE AÇÃO DO CARBENDAZIM}

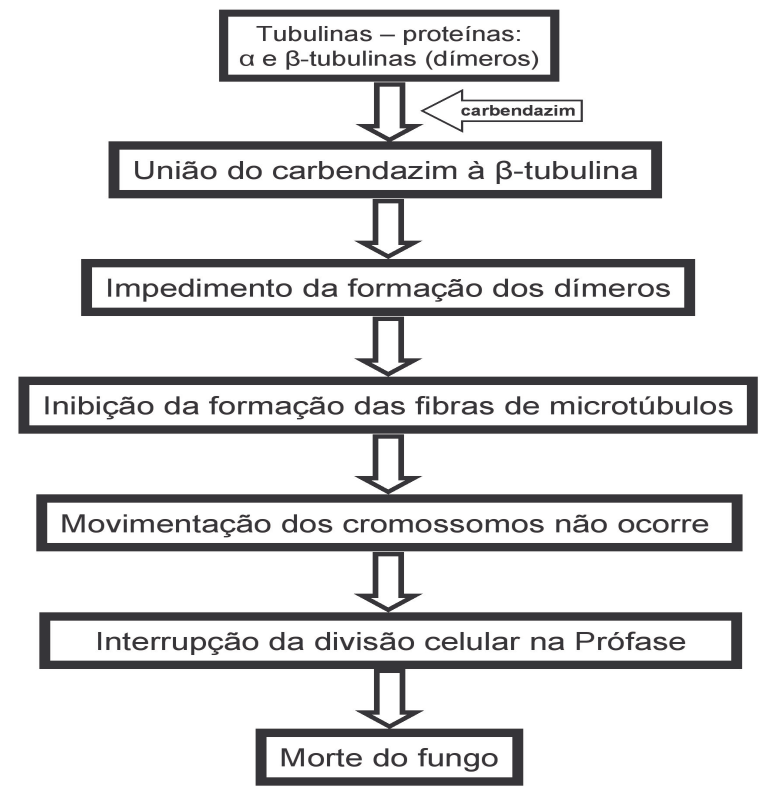

\section{PROPRIEDADES FÍSICO-QUÍMICAS}

O fungicida carbendazim (fórmula molecular $\mathrm{C}_{9} \mathrm{H}_{9} \mathrm{~N}_{3} \mathrm{O}_{2}$ ), sólido cristalino branco, apresenta massa molar igual a $191,2 \mathrm{~g} \mathrm{~mol}^{-1}$ e pressão de vapor de $<1 \times 10^{-7} \mathrm{~Pa}\left(20^{\circ} \mathrm{C}\right)$ (IPCS, 2006). A Tabela 1 mostra outras propriedades físico-químicas desse fungicida.

Propriedades Físico-Quím icas

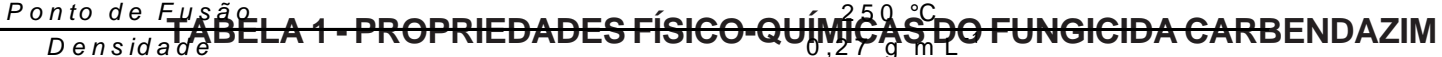

Coeficiente de partição n-octanol-água

Constante de Henry $\left(20^{\circ} \mathrm{C}\right)$

$1,02 \times 1,49$

atm $\mathrm{m}^{3} \mathrm{~mol}$

$8,0 \mathrm{~m} \mathrm{~g} \mathrm{~L}^{-1}\left(\mathrm{pH}^{7}\right)$

$7,0 \mathrm{~m} \mathrm{~g} \mathrm{~L}^{-1}\left(\mathrm{pH}^{2}\right)$

Solubilidade em água

$300 \mathrm{mg} \mathrm{L}^{-1}$ (etanole acetona)

Solubilidade em solventes orgânicos

$100 \mathrm{mg} \mathrm{L}^{-1}$ (clorofórm io)

$36 \mathrm{~m} \mathrm{~g} \mathrm{~L}^{-1}($ benzeno)

$0,5 \mathrm{mg} \mathrm{L}^{-1}$ (hexano)

Fonte: IPCS $(2006)$.

\section{CARBENDAZIM NO MEIO AMBIENTE E ECOTOXICOLOGIA}

A duração do efeito do pesticida e sua permanência no meio ambiente estabelecem a persistência desse composto, que também é influenciada pela sua estrutura química (CARDOSO, TSAI e NEVES, 1992) e condições abióticas e bióticas do meio ambiente (SILVA et al., 1999). O desaparecimento dos pesticidas no solo pode ocorrer mediante diferentes processos como, volatilização, degradação química (hidrólise) ou fotodegradação. Entretanto, em muitas circunstâncias, a perda da atividade biológica de ampla variedade de pesticidas ocorre pela atividade da comunidade microbiana (CARDOSO, TSAI e NEVES, 1992; ALEXANDER, 1981).

Estudos sobre a persistência dos fungicidas benzimidazóis no meio ambiente apresentam resultados variáveis, porém sua permanência é prolongada causando contaminação ambiental. $O$ tempo de meia-vida do carbendazim é de 3-6 meses em turfa, 1-2 meses em sedimento de rio sob 
condições aeróbias e 25 meses sob condições anaeróbias. Resíduos de carbendazim e de seus metabólicos são fortemente ligados ou incorporados à matéria orgânica do solo pelo anel imidazol da molécula do fungicida, tornando-os persistentes por mais de 3 anos (FERNANDEZ et al., 2001; IPCS, 2006).

O carbendazim apresenta pequeno efeito sobre a comunidade microbiana do solo, porém mostrou-se letal para minhocas. É altamente tóxico para a comunidade aquática: anfíbios (efeitos genéticos e mortalidade), plantas aquáticas (reprodução), crustáceos (mortalidade), peixes (bioacumulação e mortalidade), fungos, (desenvolvimento e reprodução), moluscos (intoxicação e mortalidade) e plâncton (intoxicação, crescimento, reprodução e mortalidade) (PAN, 2006). É pouco tóxico para pássaros e atóxico para abelhas (IPCS, 2006).

\subsection{DEGRADAÇÃO ABIÓTICA}

BOUDINA et al. (2003) estudaram a fotólise do fungicida carbendazim em soluções aquosas, usando fonte de luz ultravioleta (UV) e simulador de luz solar. De acordo com os resultados experimentais, o carbendazim revelou-se estável no escuro e em condições ambientais. O pH das soluções influenciou o comportamento fotoquímico do fungicida, sendo a velocidade da fotodegradação consideravelmente acelerada em condições alcalinas. Três fotoprodutos, emitidos a partir da quebra do anel benzimidazol, foram identificados em água pura: 2-aminobenzimidazol, isocianato de benzimidazol e monocarbometoxiguanidina (Figura 3). Esse último produto apresentou grande estabilidade podendo acumular-se no ambiente.

\section{FIGURA 3 - MECANISMO DE FOTODEGRADAÇÃO DO CARBENDAZIM}

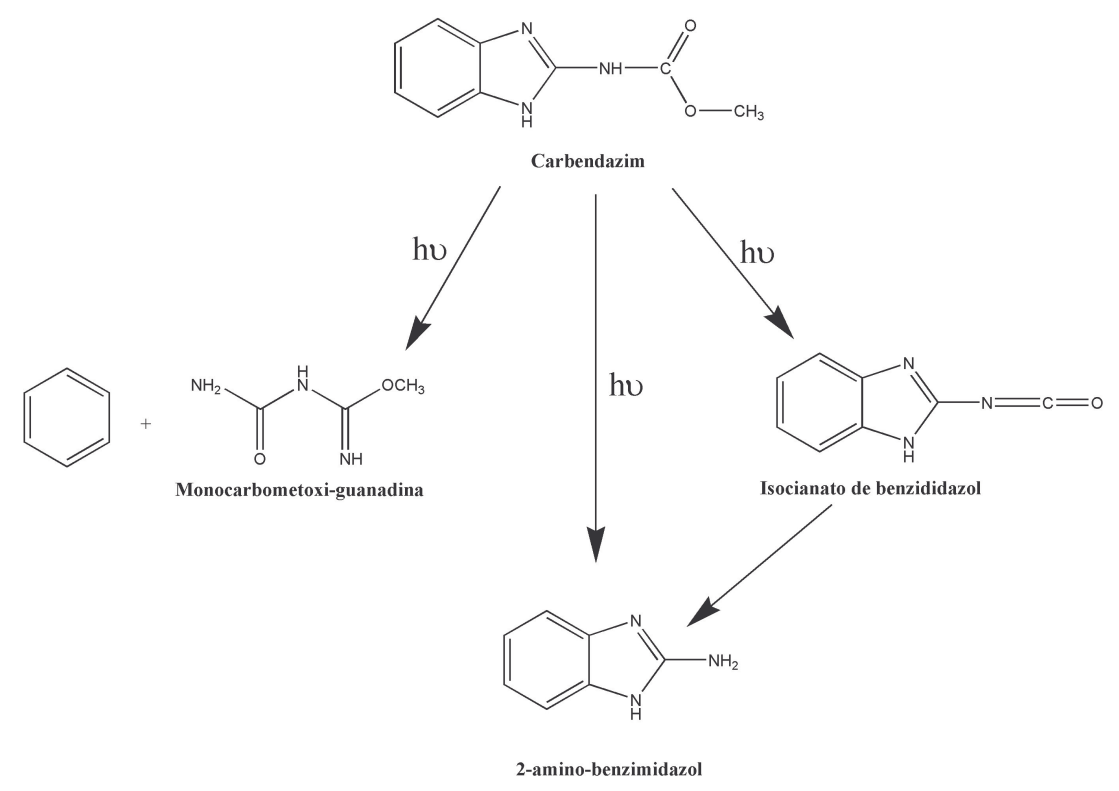

PANADÉS, IBARZ e ESPLUGAS (2000) estudaram a cinética da fotodecomposição do carbendazim em soluções aquosas com diversos valores de $\mathrm{pH}$, porém usando diferentes concentrações de oxigênio dissolvido. Verificaram que o processo de fotodegradação seguiu cinética de primeira ordem e que a velocidade de degradação do carbendazim aumentou não somente com o pH, mas também com a concentração de oxigênio dissolvido nas soluções.

A fototransformação do fungicida carbendazim foi pesquisada por MAZELLIER, LEROY e LEGUBE (2002). Em soluções aquosas, o carbendazim apresentou propriedades de base fraca e pKa de 4,53 \pm 0,07 . Ambas as formas do carbendazim apresentaram emissão fluorescente, cujos comprimentos de onda máximos foram $393 \mathrm{~nm}$ para a forma protonada e $305 \mathrm{~nm}$ para a neutra. Resultados semelhantes 
foram relatados por BOUDINA et al. (2003) e PANADÉS, IBARZ e ESPLUGAS (2000), confirmando que maior concentração de oxigênio aumenta a velocidade de fototransformação em soluções alcalinas $(\mathrm{pH}=8,4)$. A determinação dos produtos de degradação por cromatografia a líquido, acoplada à espectrometria de massa, identificou o 2-aminobenzimidazol como produto majoritário.

MAZELLIER et al. (2002) propuseram a transformação do fungicida carbendazim por radicais hidroxil, gerados por fotólise do peróxido de hidrogênio em solução aquosa na ausência e presença de íons hidrogenocarbonatos. Na ausência de íons hidrogenocarbonatos e usando altas concentrações de peróxido de hidrogênio, a constante de velocidade (ordem dois) da reação de radicais hidroxila com carbendazim foi de 2,2 $\times 10^{9} \mathrm{~L} \mathrm{~mol}^{-1} \mathrm{~s}^{-1}$. A identificação dos principais produtos de degradação mostrou a existência de dois diferentes sítios de reação: o anel benzênico e o grupo metil. Na presença de íons hidrogenocarbonatos, o modelo cinético forneceu evidência de outras rotas para a degradação do carbendazim com possível envolvimento do radical carbonato.

\subsection{DEGRADAÇÃO BIÓTICA}

HELWEG (1977), um dos primeiros a estudar a biodegradação do fungicida benomil, considerou seu derivado carbendazim como fonte pobre de carbono e sugeriu que a biodegradação desse fungicida fosse processo de cometabolismo. Outros autores (FUCKS e DEVRIES, 1978) relataram que os anéis aromáticos dos benzimidazóis são recalcitrantes à degradação microbiológica, ao contrário da porção alifática facilmente hidrolisada (FLEEKER et al., 1974).

WOODCOCK (1978), pesquisando a degradação microbiana do fungicida benomil, observou uma rápida perda do fungicida no solo que não poderia ser atribuída à lixiviação ou absorção pelas plantas. Posteriormente, em laboratório, foi constatada perda muito rápida do fungicida em solos previamente tratados com benomil ou carbendazim. Em solos não-tratados com esses fungicidas não foi observada tal biodegradação. A degradação acelerada de carbendazim pode ser aumentada ou conferida em solo sem histórico de aplicações do fungicida pela adição de quantidades minuciosas de solo pré-condicionado com aplicações anteriores de carbendazim (YARDEN, AHARONSON e KATAN, 1987). Em 1984, RAJAGOPAL et al. (1984) propuseram a rota (apresentada na Figura 4) para a degradação do benomil no solo e em culturas microbianas.

KAUFFMAN et al. (1985) postularam que a rápida degradação do pesticida está ligada com a exposição prévia do microrganismo ao pesticida, ou a compostos relacionados mediante aplicações sucessivas do mesmo pesticida. Isto resultaria no enriquecimento do solo com microrganismos capazes de degradar tais compostos. Esse fenômeno foi observado para vários pesticidas, entre os quais o carbendazim (YARDEN et al., 1990). Segundo esses autores, a degradação acelerada pode envolver modificações quantitativas e qualitativas na atividade microbiana e no processo concomitante de degradação do pesticida no solo.

YARDEN et al. (1990) estudaram o envolvimento de fungos e bactérias na biodegradação de carbendazim e de outros benzimidazóis no solo. Estabeleceram relação entre a estrutura química e a degradação microbiológica acelerada desses fungicidas, que pode ser utilizada para elucidar o mecanismo que governa a persistência desses compostos no solo. Dentre os benzimidazóis testados, somente os fungicidas substituídos via o grupo amino na posição 2 (2-aminobenzimidazol e carbendazim) aceleraram a degradação. Tal fato indica que essa substituição é necessária para que a biodegradação de carbendazim no solo seja mais eficiente. YARDEN et al. (1990) isolaram o fungo Alternaria alternata de solos tratados com carbendazim, que foi capaz de biodegradar esse fungicida. Observaram ainda degradação mais rápida por culturas bacterianas originadas de solos previamente tratados com carbendazim do que daquelas provenientes de solos sem prévio tratamento. Comparando a biodegradação de carbendazim pela inoculação de culturas bacterianas com a do fungo $A$. alternata em solos sem prévio tratamento, somente a primeira inoculação resultou em biodegradação acelerada do fungicida. Tal fato sugere que enquanto o fungo contribui para a dissipação de carbendazim no solo, as bactérias exercem maior infuência na biodegradação desse fungicida. 


\section{FIGURA 4 - MECANISMO DE BIODEGRADAÇÃO DO CARBENDAZIM}

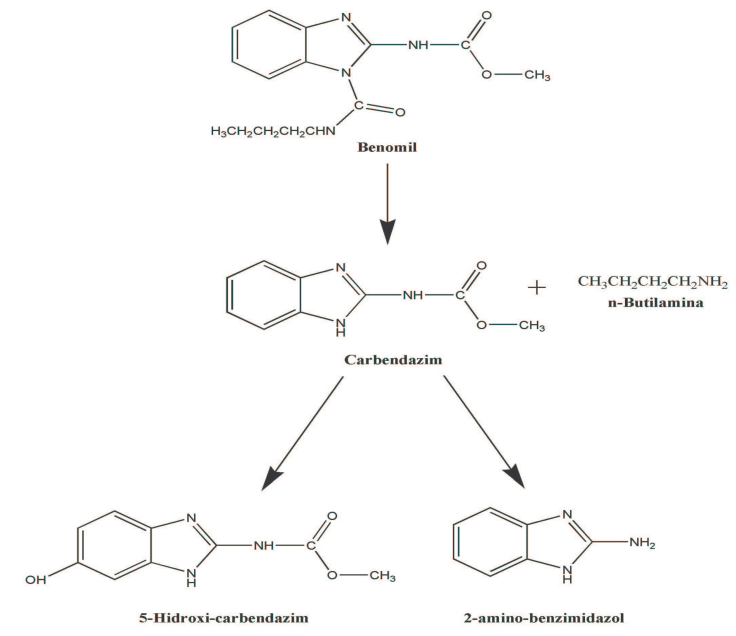

SILVA, FAY e MELO (1996) relataram a biodegradação do carbendazim pelo fungo Phanerochaete chrysosporium. Esse fungo lignocelulolítico, agente causal da podridão branca em madeira, mostrouse eficiente como degradador de carbendazim. O fungo foi cultivado na presença de carbendazim por vários dias. Os resultados obtidos por SILVA, FAY e MELO (1996), mediante determinação dos resíduos por cromatografia, demonstraram que o fungicida é rapidamente degradado por esse fungo (aproximadamente $76 \%$ nos primeiros 6 dias de incubação). O complexo enzimático degradador de lignina do Phanerochaete chrysosporium foi efetivo na oxidação e imobilização de diversos xenobióticos altamente recalcitrantes, como DDT (2,2-Bis-(p-clorofenil)-1, 1,1-tricloroetano) e TCDD (isômero da dioxina), tornando-o potencial agente de biorremediação de áreas contaminadas por poluentes complexos.

A biodegradação do carbendazim utilizando consórcio de microrganismos obtidos em diferentes tipos de solo, abordada por NAGASE et al. (2006) e PATTANASUPONG et al. (2004), mostrou-se promissora para águas contaminadas.

\section{TOXIDEZ DO CARBENDAZIM}

As principais vias de exposição do homem ao carbendazim envolvem a dieta e os processos de fabricação e manuseio do produto. Devido à pequena toxicidade aguda para mamíferos e baixa taxa de absorção dérmica, a intoxicação por essas substâncias é pouco provável nas condições normais de uso. Estudos com ratos revelaram que o carbendazim foi bem absorvido após exposição por via oral (cerca de 80 a 85\%), mas muito menos em se tratando de exposição dérmica (BASF, 2006).

Em animais, o carbendazim é metabolizado em (5-hidróxi-1H-benzimidazol-2-il) carbamato e outros metabólitos polares que são rapidamente excretados pelas fezes e urina. $O$ carbendazim causa irritações na pele humana, entretanto apresenta toxidez aguda muito baixa para os seres humanos (IPCS, 2006; BASF, 2006).

A distribuição tecidual do carbendazim demonstrou que não ocorreu bioacumulação em ratos e sua concentração mais alta após administração oral (< $1 \%$ da dose) foi determinada no fígado. $O$ carbendazim e seus metabólitos também foram detectados nos rins de galinhas e de mamíferos de grande porte (vacas) e em níveis insignificantes nos outros tecidos. Pequenas quantidades de (5hidróxi-1H-benzimidazol-2-il) carbamato foram encontradas no leite de vacas tratadas com administrações de carbendazim via dieta. Em ratos, o carbendazim foi excretado pela urina e fezes num período de 72 horas após a administração oral. Estudos mostraram que o carbendazim afetou também algumas enzimas microssomais hepáticas (IPCS, 2006; BASF, 2006).

Os sintomas de intoxicação crônica em seres humanos são hiperfibrinogenemia, aumento na 
atividade fibrinolítica do sangue e irritação não-específica dos elementos reticuloendoteliais que sintetizam fibrinógeno no fígado. Os efeitos neurológicos incluem polineurite simpática das mãos, disfunções simpático-vasculares, síndromes asteno-simpáticos e asteno-neuróticos, insuficiência hipotálamomesodiencefálica, disfunções da estrutura mesodiencefálica e depressão constante da atividade alfa (BASF, 2006).

A exposição crônica à formulação pode ocasionar disfunções do sistema nervoso central, dano ocular e dermatite, bem como disfunções hepáticas, renais, estomacais, anemia e outras disfunções sanguíneas. Efeitos mutagênicos e carcinogênicos não foram observados em seres humanos. Estudos em laboratório mostraram que o carbendazim gera alguns efeitos em ratos como, malformação, redução do peso fetal, diminuição da fertilidade e alguns tumores. Contudo, não foram observados efeitos carcinogênicos ou mutagênicos (IPCS, 2006; BASF, 2006).

\section{CONCLUSÃO}

Devido ao uso intenso de carbendazim, esse fungicida tornou-se poluente muito persistente no solo e na água.

Os estudos de degradação e dos efeitos toxicológicos não são focados somente no desaparecimento do carbendazim, mas também nos produtos intermediários que definem o real impacto ambiental dos poluentes. Tais estudos são importantes para o isolamento e caracterização de microrganismos capazes de degradar o fungicida, e também para o desenvolvimento de processos abióticos (fotodegradação) a serem utilizados no tratamento de água e solo poluídos.

\section{ABSTRACT}

\section{CARBENDAZIM AND THE ENVIRONMENT: DEGRADATION AND TOXICITY}

This article presents a brief review about the fungicide carbendazim, widely used in fruits and vegetables cultures in Brazil. It was approached mainly the degradation (abiotic and biotic) and the toxic effects of carbendazim in man and animals. The degradation studies are important for the isolation and characterization of the microorganisms capable to degrade the fungicide, and also for the development of abiotic processes (photodegradation) which can be used for the treatment of polluted water and soil.

\section{KEY-WORDS: DEGRADATION; FUNGICIDE - TOXICITY; CARBENDAZIM.}

\section{REFERÊNCIAS}

1 ALEXANDER, M. Biodegradation of chemical of environmental concern. Science, v. 211, p. 132-138, 1981.

2 ANVISA. Agência Nacional de Vigilância Sanitária. Reavaliação de produtos agrotóxicos Disponível em: http:// www.anvisa.gov.br/toxicologia/reavaliação/ index.htm. Acesso: 28 mar. 2006.

3 BASF. The Chemical Company. Informativos técnicos: modo de ação-benzimidazóis. Disponível em: http:// www.agro.basf.com.br/produtos/informativo/fungicidas/modo_de_acao_princ/benzimidazoles/ benzimidazoles.asp?area=2. Acesso: 28 mar. 2006.

4 BOUDINA, A; EMMELIN, C.; BAALIOUAMER, A.; GRENIER-LOUSTALOT, M. F.; CHOVELON, J. M. Photochemical behaviour of carbendazim in aqueous solution. Chemosphere, v. 50, p. 649-655, 2003.

5 CARDOSO, E. J. B. N.; TSAI, S. M.; NEVES, M. C. P. Microbiologia do solo. Campinas: Sociedade Brasileira de Ciências do Solo, 1992.

6 DAVIDSE, L. C. Benzimidazole fungicides: mechanism and modes of action. DELF, C.J. (ed). Fungicide resistance in North America. Saint Paul: American Phytopathological Society, 1988.

7 FERNANDEZ, M.; RODRIGUEZ, R.; PICO, Y.; MANES, J. Liquid chromatographic-mass spectrometric determination of post harvest fungicides in citrus fruits. J. Chromatogr. A, v. 912, p. 301-310, 2001. 
8 FLEEKER, J. R.; LACY, H. M.; SCHULTZ, I. R.; HOUKUM, E. C. Persistence and metabolism of thiophanate-methyl in soil. J. Agric. Food Chem., v. 22, p. 592-595, 1974.

9 FUCKS, A.; DEVRIES, F. W. Bacterial breakdown of benomyl. Antonie Leeuwenhoek., v. 44, p. 293-292, 1978.

10 HELWEG, A. Degradation and adsorption of carbendazim and 2-aminobenzimidazole in soil. Pestic. Sci., v. 8, n. 1, p. 71-78, 1977.

11 HUTSON, D. H., JEWESS, T. R. Carbendazim. Cambridge (UK): Royal Society of Chemistry, 1999.

12 IPCS. International Programme on Chemical Safety. Carbendazim. Disponível em: http://www.inchem.org/documents/ icsc/icsc/eics1277.htm. Acesso: 28 mar. 2006.

13 KAUfFMAN, D. D.; KATAN, J.; EDWARDS, D. F.; JORDAN, E. G. Microbial adaptation and metabolism of pesticides. Totowa: J. L. Hilton, 1985.

14 LEROUX, P. Modes d'action des produits phytosanitaires sur les organismes pathogènes des plantes. C. R. Biologies, v. 326, p. 9-21, 2003.

15 MAZELLIER, P.; LEROY, E.; LEGUBE, B. Photochemical behavior of the fungicide carbendazim in dilute aqueous solution. J. Photochem. Photobiol. A, v. 153, p. 221-227, 2002.

16 MAZELLIER, P.; LEROY, E.; DE LAAT, J.; LEGUBE, B. Transformation of carbendazim induced by the $\mathrm{H}_{2} \mathrm{O}_{2} / \mathrm{UV}$ system in the presence of hydrogenocarbonate ions: involvement of the carbonate radical. New J. Chem., v. 26, p. 17841790, 2002.

17 NAGASE, H.; PATTANASUPONG, A.; SUGIMOATO, E.; INOUC, M.; HIRATA, K.; TANI, K.; NASU, M.; MIYAMOTO, K. Effect of environmental factors on performance of immobilized consortium system for degradation of carbendazim and 2,4-dichlorophenoxyacetic acid in continuous culture. Biochemical Engineering Journal, v. 29, n. 1-2, p. 163168, 2006.

18 PAN. Pesticide Action Network. Carbendazim: identification, toxicity, use, water pollution potential, ecological toxicity and regulatory information. Disponível em: http://www.pesticideinfo.org/Detail_Chemical.jsp?Rec_Id=PC32862. Acesso: 30 mar. 2006

19 PANADÉS, R.; IBARZ, A.; ESPLUGAS, S. Photodecomposition of carbendazim in aqueous solutions. Water Res., v. 34, n. 11, p. 2951-2954, 2000.

20 PATTANASUPONG, A.; NAGASE, H.; INOUC, M.; TANI, K.; NASU, M.; HIRATA, K.; MIYAMOTO, K. Ability of a microbial consortium to remove pesticides, carbendazim and 2,4-diclorophenoxyacetic acid. World Journal of Microbiology \& Biotechnology, v. 20, p. 517-522, 2004.

21 PICININI, E.C. Fungicidas benzimidazóis. Revisão Anual de Patologia Vegetal, v. 2, p. 357- 409, 1994.

22 RAJAGOPAL, B.S.; BRAHNAPRAKASH, G.P.; REDDY, B.R.; SINGH, U.D.; SETHUNATHAN, N. Effect and persistence of selected carbamate pesticides in soil. Residue Reviews, v.93, p. 6-19, 1984.

23 SANCHEZ-RASERO, F.; ROMERO, T. E.; DIOS, C. G. Liquid chromatographic determination of carbendazim in presence of some normal soil constituents with photodiode-array detection. J. Chromatogr., A, v. 538, p. 480-483, 1991.

24 SANDAHL, M.; MATHIASSON, L.; JONSSON, J. A. Determination of thiophanate-methyl and its metabolites at trace level in spiked natural water using the supported liquid membrane extraction and the microporous membrane liquidliquid extraction techniques combined on-line with high-performance liquid chromatography. J. Chromatogr. A, v. 893, p. 123-131, 2000.

25 SILVA, C. M. M. S.; DE MELO, I. S.; MAIA, A. H.; ABAKERLI, R. B. Isolamento de fungos degradadores de carbendazim. Pesq. Agropec. Bras., v. 37, n. 7, p.1255-1264, 1999.

26 SILVA, C. M. M. S.; FAY, E. F.; MELO, I. S. Degradação do fungicida carbendazim por Phanerochaete chrysosporium. Fitopatol. Bras., v. 21, n. 4, p. 498-496, 1996.

27 SINGH, M. P.; CHIBA, M. Determination of benomyl and its degradation products by chromatographic methods in water, wettable powder formulations, and crops. J. Chromatogr. A, v. 643, p. 249-260, 1993.

28 YARDEN, O.; AHARONSON, N.; KATAN, J. Accelerated microbial degradation of methyl benzimidazole-2-ylcarbamate in soil and its control. Soil Biol. Biochem., v. 19, p. 735-739, 1987.

29 YARDEN, O.; SALOMON, R.; KATAN, J.; AHARONSON, N. Involvement of fungi and bacteria in enhanced and nonenhanced biodegradation of carbendazim and other benzimidazole in soil. Can. J. Microbiol., v. 36, p. 15-36, 1990.

30 WOODCOCK, D. Microbial degradation of fungicides fumigantes and nematicides. New York: Pesticide Microbiology, 1978. 